\title{
THE OBSERVATIONS ABOVE THE VOLUME OF THE LANGUAGE
}

\section{Silvina Mihaylova, sbojidarova@yahoo.com}

Sofia University "St. Kliment Ohridski", Sofia, Bulgaria

Abstract: The article treat of the complication and the simplification like a language processes which present the movement of the language unit and delineate the volume of the language.

Keywords: Volume; Syntactical Frame

\section{НАБАЮАЕНИЯ НАА ОБЕМА НА ЕЗИКА}

\section{Си^вина Михай^ова, sbojidarova@yahoo.com}

Софрийски университет "Св. Св. КА. Охридски", Софрия, Бьлгария

Резюме: В статията се разгежАат усложняването и опростяването като езикови процеси, които представят Авижението на езиковата единица и очертават обема на езика.

КАючови Ауми: обем, синтактична рамка

Изпалането и вмъкването на езикова елиница както в ^ексема, така и в изречение ни отправя към обем на езика. Още Е. Сепир посочва, че обемното прелставяне на езика го разкрива много поАетайлно и по-богато (Sepir, 1993, р. 168). Измененията, които настьпват в езика говорят за промени и в неговия обем като разкриват и Авижението му. На морфрологично ниво и на синтактично равнище сьществуват същите процеси на изпалане и вмъкване, разширяване, редупликация и т. н. на езиковата еАиница, а тези процеси неминуемо рефрлектират и върху обема на езика. Същото принципно важи и за лексикално ниво.

Тук искам Аа се спра на няколко разнородни изследвания на езиковеАи, които са работили в различни сорери на езика, и са стигнали АО еАнакви наблюАения в своите разработки, отнасящи се и $А$ со семантиката на езиковата еАиница. 
Както знаем, в български език в миналото сме имали четири глагола, които са изпьлнявали функцията на спомагателни, но развитието на езика ги е свело АО еАин глагол в съвременния български език. Отпалането на спомагателните глаголи в тази им фуункция и свиването им Ао еАин спомагателен глагол Анес разкрива тяхното редуциране и Авижение.

В съвременния английски език формите на глагола, например 'играя' to play съвпаАат за всички ^ица и числа С изк^ючение еАинствено на фоормата за 3 ^. еА. Ч., в която се появява 'S' в сегашно време. СлеАователно настьпилото опростяване на спрежението проправя пьтя на английския към аналитизьм (Spasov, 1972).

В съвременния фрренски език, който пази своите спрежения, местоимението ON, като пьлнозначна елиница, означава 3 ^. еА. ч. Това местоимение е развило и фрункция за изразяване на неопределеност. То се ползва с изключителна честотност в езика от еАна страна, а от Аруга страна измества мицата и числото на цели спрежения. Веннага си представяме еАин глагол, чието спрежение се състои само от еАна фрорма - тази на 3 ^. ел. ч. Ето как обемьт на спрежението е намаля^ с неговото опростяване. Налице е и икономията в езика. И това е валилно за всички глаголи, от всички спрежения. Спреженията съществуват, но като по-сложни и неудобни за употреба остават в известна степен на зален п^ан в съвременния разговорен фрренски език. Аокато местоимението ON е предпочитано и когато говорещото мице желае aа скрие или предпочта $а \mathrm{a}$ не назове конкретно извьршителя на Аействието, или когато това уточнение не е необходимо според него. В някоИ случаи ON се използва пораАи икономия, а е възможна и някаква Аруга причина. По такъв начин в еАна еАинствена езикова фрорма се фокусират фуункциите и значенията на всички останали фрорми на съответния глагол. С Аруги Ауми местоимението ON редуцира обема на цели спрежения в съвременния говорим фрренски език. В същото време ясно изпьква колко много функции е способно Аа извьрши и извьршва това местоиение и Ао каква степен обемьт на спрежението се свива за сметка на фуннциите и значенията, които то изпьлнява. А това обстоятелство разкрива как фрормалното опростяване на обема 
на езиковата еАиница се извьршва като компенсация на семантичното му усложняване (Feuillet, 1994-1995).

Ст. Стоянов отбелязва, че: "В някои глаголни форми основната наставка се е сля^а с мичното окончание, порали което основата не може $\Delta$ а се изолира. Такова положение имаме сега във форомите на глаголите от I и от II спрежение в сег. време, 1 ^. еА. ч. и 3 ^. мн. ч., напр.: бера [берь] ... берат [берьт]. Основната наставка на този глагол в сегашно време е -е-". В посочените орорми наставката не личи, защото вследствие на закономерен фонетичен развой още на праславянска почва се е сляла с пьрвоначалното ^ично окончание. Това означава, че наставката представлява знак за цяло спрежение и елновременно с това е основен, съставящ елемент на окончанието. Като маркер за цяло спрежение тя извършва и разкрива обобщаваща, абстрактна фоункция на тази морорема като същевременно определя приналлежността на глагола към съответно спрежение. Отново се сбльскваме с $а в е$ функции, които езиковият елемент извършва еАновременно, но интригуващото е, че еАната фоунция е абстрактна, тъй като организира и обелинява глаголните фоорми в спрежение, а другата е конкретна, изразяваща окончанието. Парадоксалното е, че и Авете фоункции, несьвместими на прьв поглеА, се реализират от еАна и съща морорема, т. е. от от еАин и същ езиков елемент. Примерът разкрива обединение на форма (конкретността, изразена чрез окончание) и сьльржание (фокоусирано в абстрактността на знака, на маркера за спрежение).

Същото положение се установява във фрренски език (Mantchev, 1976, pp. 193-194).

В съвременния италиански език, обаче, иноринитивната характерна гласна се изпуска във формите за бъдеще и за сегашно условно време, въпреки че тя определя спрежението. Следователно еАин И същ езиков елемент изпьлнява Аве коренно противоположни, несъвместими функции. Щом функциите са противоположни, очевиАно е, че и характеристиките, и свойствата на езиковия елемент са също противоположни, а това още веАнъж Аоказва нарастналия обем на езиковия елемент в семантично отношение. 
Разработвайки начините на глаголното действие, К. Иванова анализира категорията прелелност/непрелелност, която като абстрактна категория включва цялата глаголна лексика. Авторката отбелязва, че тази категория се намира във врьзка с начините на Аействие и дава отражение върху вила. Според нея всички начини на Аействие, които притежават както фрорми за несвьршен вил, така и фрорми за свършен виА, са комплектувани от преАелни глаголи (Ivanova, 1983, р. 288). При непределните глаголи е по-сложно, понеже Аействието по своята същност изкюючва наличието на предел. Вьпреки това при някоИ от тях, ГАаголите, които С еАни От значенията сИ приналлежат кьм общорезултативния, а с Аруги - кьм еволютивния начин на Аействие, се проявяват като пределни. И тук се повтаря същото - еАин езиков елемент, гАагол, изпьлнява противоположни фуункции и значенията му са противоположни.

Като Аруг пример може $а$ а се посочи глаголния виА, разработен от В. Станков. Както знаем, при Авувидовите глаголни Авойки фрормите на тези глаголи изразяват Авата глаголни вида еАновременно. С Аруги Ауми и Авата виАа параАоксално се изразяват от еАна и съща езикова еАиница - глагола, колкото и значенията им Аа са противоположни. Посочените фоорми на глаголите притежават Аостатьчно широка и абстрактна семантика, а това е еАно от зальлжителните условия, те $\Delta \mathrm{a}$ се сближават в значенията си, тьй като се стига в определен момент Ао размиване на значенията им. Вероятно значенията на тези глаголни форми са се Аоближили Ао такава степен, че се сьздава впечатление за тяхното като че ми уелнаквяване. По такъв начин елна глаголна форма, еАин езиков елемент се явява изразител и на свършен, и на несвършен вил. По-важното е, че глаголната фоорма, т. е. еАин езиков елемент е носител параАоксално на противоположни качества в определена ситуация. Тя елноврменно извършва фрункцията, типична за Авата виАа, които са респективно противоположни. Това се случва винаги при определено условие. В. Станков посочва условията, при които настьпва уеднаквяването на фрормите им. Те имат неутрален характер в момент, когато е настьпило изблеАняване на тяхното типично видово значение, вслеАствие на което е възможно взаимопроникването 
и взаимозамяната им (Stankov, 1980, р. 47). Неутралният характер на

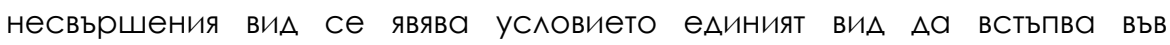
фрункцията на другия глаголен вил. СпореА мен, неутрализирани по такъв начин, те се заменят взаимно и осьществяват Аискретно смяната на глаголния виА. Ако приемем, че тяхното неутрализиране или загубата на типичното им виАово значение преАставлява формално опростяване, то тази глаголна орорма е натоварена с характеристиките и свойствата на Авата глаголна вила. Очертава се съвсем ясно обаче как формалното опростяване довежла Ао семантичното обогатяване и усложняване на глаголната форома.

Спореа К. Иванова словообразователният елемент може да представя различни начини на Аействие, когато е свързан с различни основи, както и еАин и Същ начин на гАаголно Аействие може $а$ бъ $е$ изразен от глаголи, офрормени с различни фрормални показатели (Ivanova, 1983, р. 283). Отново опираме Ао същия фракт - еАна езикова елиница (словообразувателния елемент) при определени условия (когато елементьт е свързан с различни основи), е способна $а$ а изразява и категорията начин на глаголно Аействие. Това означава, че елна езикова еАиница е способна и натоварена $А$ изразява различни начини на глаголно Аействие при далено условие. Отново е налице формалното опростяване, което натоварва езиковия елемент в семантично отношение.

А. Н. Тихонов твьраи, че механизмьт за образуване на лексеми през степен, т. н. "чересступенчатого словообразования" се управлява от закона на аналогиите. Съгласно този закон причастия и съществителни, означаващи Аействия възникват без глагол по образец на съществуващите в езика структурни типове причастия и отглаголни съществителни (Tihonov, 1985, р. 47). Както отбелязва езиковедьт, възможността за непосреАствени смислови връзки межАу Аумите, които приналлежат към различни степени на словообразуването, преАпоставят благоприятни условия за образуването на Ауми с пропуск на каквото и Аа било количество словообразувателни звена. Ето защо авторьт отАава голямо значение на този вил словообразуване (Tihonov, 1985 , р. 47). Ученият отбелязва, че този виА словообразуване прониква във 
взаимоотношенията межлу еннокоренните Ауми, преобразува ги, като семантичните отношения се опростяват, а се усложняват форомалноструктурните отношения межАу родствените Ауми, участващи в словообразувателната редица. Възникват нови молели на словообразуване, нови словообразувателни фрорманти. С тях е свързано появяването в езика на много съставни префрикси и на словообразувателни форманти (Tihonov, 1985, р. 47), което веднага представя различен и полвижен обем на езика.

Ето как на словообразувателно равнище са установени сьщите процеси на усложняване и опростяване на отношенията межАу определен кръг еАнокоренни, родствени Ауми. А семантичните изменения свидетелстват за реолектиране навярно на същите понякога Авижения на еАиницата.

Процеси на усложняване, опростяване и межлинен характер на езикова единица установява и Ст. Петрова. Тя счита, че межАинният характер на единицата засяга слетите изречения (Petrova, 2008), (Petrova, 2009). Те са усложнено прости и опростено сложни. СпореА нея усложняването е в резултат на добавяне на обособени или еАнородни части. Именно тук, при Аобавянето ученият вижАа усложнение на формално-структурните отношения, а семантичните отношения понякога не са осезаеми, дори в някои случаи се опростяват в смисъл, че значението се конкретизира, дообяснява и изяснява. Фактьт, че в опростените сложни изречения се включват непьлни изречения, говори за изпадане на някоя част от изречението, за елипса в изречението, което представлява опростяване във орормалноструктурно отношение и усложняване в семантично отношение. Т. е. и на синтактично равнище, както се посочи и на словообразувателно, и на морфолоично ниво, се наблюАават еАни и същи езикови изменения.

Анализирайки съюзите Ст. Петрова отбелязва, че в межАинните звена се очертава и изпьква отново не само как се извьршва свързването межАу езиковите нива, но и най-общо се проследява "придвижването" и изменението на единиците. Фактьт, че някои съюзи Стоят межАу съчинението и полчинението, ги разкрива съответно като съчинителни и поАчинителни съюзи. СлеАователно в тяхната природа е 
заложена тази способност - $а$ изразяват противоположни фрункции. Още по-забележителното е, че посочените фонкции са присъщи на еАни и същи езикови еАиници. Остава неясно - кое определя коя

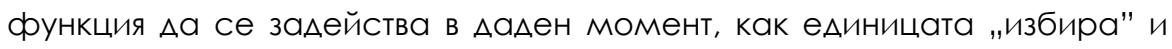

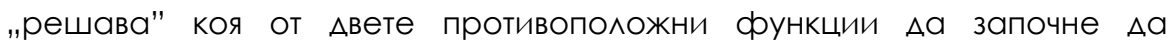
функционира в определена езикова елиница в съответен момент. Не се разбира също така на какво се Аьлжи тази способност на езиковата елиница. Защо съществува тя като езикова характеристика и каква функция и роля изпьлнява - за Аа осъществява гъвкавост и повратливост, и по такъв начин в крайна сметка да спомага за непрекъснатостта и Авижението на езика. Отговорите на тези въпроси остават открити засега.

ИзслеАвайки отношенията межАу частите на речта и частите на изреченията езиковедьт отбелязва, че $\Delta$ алена част на речта може $\Delta$ а изпьлнява фрункция на различни части на изречението (макар някои от тях Аа имат преимуществено опрАелена синтактична фрункция). С Аруги Ауми морорологичните еАиници, изразени чрез семантичнограматичните категории, т. е. чрез частите на речта изпьлняват и функции на синтактични категории, съответстващи на ниво синтаксис на частите на изречението. Ето как езикови елиници на ниво морфрология изпьлняват и синтактични фрункции при опреАелени условия, напр. "преимуществено". В същото време Ст. Петрова ни представя и обратното - как далена част на изречението (пол^ог, Аопьлнение и т.н.) се изразява с различни части на речта, макар и някои от тях $\Delta$ а се изразяват преимуществено от определена част на речта. И^и характеристиките на елементите от съответното ниво потенциално сьльржат и свойствата на елементи от Аруго равнище, което говори за

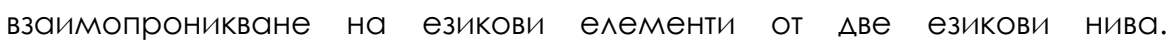
Следователно синтактичните еАиници, като части на изречението, сьльржат в себе си потенциално специориките на частите на речта, т. е. на морорологичните еАиници. Условията, които са посочени ни отвежАат $А$ пореАния параАокс - еАното условие разкрива общото межлу елементите, а другото условие подчертава конкретното и отразява спецификата на езиковите елементи. Така разбираме, че 
функцията на Аалена част на речта, например глагол отговаря на фрункцията, заАоволява фрункцията на $А$ Аена част на изречението сказуемо. Всичко казано $А$ тук Аоказва пьрво тяхната взаимозаменяемост по Аруг пьт и второ, Аоказва, че фрункциите се различават по обем - елната засяга общото межАу елементите, а Аругата фрункция отразява конкретното, специфричното, частното межАу тях. Или онова, което ги характеризира и разграничава сьщевременно пресъзаава тяхната специорика. Така научаваме, че има езикови елементи, които отразяват обелиняващото межАу елементите и такива, които Аават израз на конкретното и специфричното межАу тях. Общото между елементите се сьдьржа и разкрива чрез условието, а именно преимуществено синтактичната функция, която изпьлнява еАна част на речта. Конкретното, специфичното се позиционира в езиковите елементи, представени от различните части на речта и изпьлняващи еАна част на изречението като съществително в ролята на поАлог или Аопьлнение, глагол в ролята на сказуемо, прилагателно в ролята на определение и т. Н. По такьв начин Ст. Петрова стига до съществено заключение за мордрологичните единици, които се изразяват чрез различни части на речта на морфрологично ниво, съдьржат и отразяват конкретното, специфиичното на езиковите елементи. Аокато синтактичните еАиници - т. е. частите на изречението фрокусират в себе си обединяващото межАу езиковите елементи, т. е. общото межАу тях.

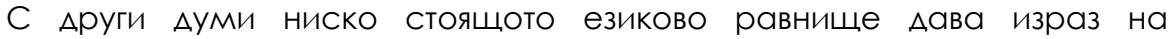
конкретното в езиковата еАиница, а по-висшестоящото ниво синтаксисьт отговаря и пресьзаава общото в нея. В крайна сметка преА нас изпькват преплетените отношения межАу мордрологичното и синтактичното ниво като същевременно ясно се очертава врьзката межАу Авете езикови равнища, което от своя страна представя обема на езиковата еАиница от съответните нива.

Взаимодействието межАУ мордрологични и синтактични езИкови еАиници се открива в съотносимостта межАУ синтактичната рамка, термин, въведен от Ст. Петрова и вила на глагола от гледна точка на системността в езика. Общото межау термините се фрокусира във възможността за избор, а именно Аали $А$ а се промени насочеността на 
СИнтактичната рамка в зависимост от иАеята, която преАстои Аа се изложи, и^и Аа не се променя, точно както и при вила на глагола. Следователно смисьльт, значението зависи от говорещия, който определя насочеността на синтактичната рамка, в съответствие с намерението $а$ а изрази далена илея. А това категорично показва, че значението е еАна от изменящите се езикови еАиници и обяснява невъзможността $\Delta а$ се обхване в елнозначна деориниция. Такава дефиниция ще се $а$ ава, но никога не би могла $\Delta а$ бъле ориксирана. Обратното, тя се променя спрямо обекта на изследване, стимулираща развитието на езика. По такъв начин ясно изпьква, че значението на езиковата единица има също обем. Оттук следва, че синтактичната рамка и виАьт Аават възможност $А$ व се превкАЮчИ От еАИН КъМ Аруг регистьр на значението - от ниво синтаксис на ниво морфология, става дума за морорологично и за синтактично значение. Освен това синтактичната рамка се изгражда от Ава елемента. ВиАьт също се състои от Ава елемента - свършен и несвършен. И Авата термина се характеризират с обем в значението, което е широко обхватно, абстрактно и като такова, е Аостатъчно неопрАелено или Авете глаголни форми се отличават с намален и конкретен обем на значението. Названието на свършения вил полсказва, че действието е ограничено, Аокато несвършен виА означава отвореност и неАвусмислено се разбира, че действието продьлжава неопределено Аокога. На тази основа - вила на глагола, се одрормят и прольлжителните времена минало несвършено време в българския език, в руски език отсъства като точно съответствие на времето, в английски и френски език съществува, като в английски има и сегашно продължително време. В арабски език съществува двуделението незавършеност/завършеност на действието. При синтактичната рамка е аналогично - еАната насоченост би дала известна, повече или по-малко определеност и ограниченост на Аействието, Аокато Аругата възможност - би офрорми^а противоположната насоченост и това е ^огично, за Аа може да се осигури и осъществи непрекъснатостта на езика и оттам развитието му. 
Така изложените анализи на учените, извьршени по съвсем самостоятелни пьтища стигат Ао еАнакво разкриване на споменатите фрормално-структурни и семантични отношения. По такъв начин в рамките само на глагола се очертава тази особеност на езиковите елементи, което несъмнено открива закономерност в езика. А същите отношения се отнасят кьм обема на езика като представят различните му състояния съобразно Аален езиков периол. Посочените отношения откриват и обогатяват от разнородни аспекти термина обем.

\section{LITERATURE ( $\triangle$ UTEPATYPA)}

Feuillet, J., (1994-1995) Grammaire comparée et typologie linguistique, Linguistique balkanique, 1-2, рр. 37-48 / [Ж. Фейе, 1994 - 1995, Сравнителна граматика и Аингвистична типология, Балканско езикознание, 1-2, р. 37 - 48].

Ivanova, K., (1983) GSBKE, Volume 2, morfologia, Sofia, Bulgaria, pp. 283-288 /[K. Иванова, 1983, ГСБКЕ, т. 2) морфология, С., С. 283-288].

Mantchev, K., (1976) Morphologie francaise, Cours theorique, Publisher: Nauka i izkoustvo, Sofia, Bulgaria.

Petrova, St., (2009) Asimetriata $\vee$ ezika (in Bulgarian), р. 98 /[Ст. Петрова, 2009, Асиметрията в езика, Sp. , с. 98].

Petrova, St., (2008), Slojno izrechenie i ezikovi ravnishta (in Bulgarian), p. 140 /[CT. Петрова, 2008, С^ожно изречение и езикови равнища, Sp, с. 140].

Sepir, E., (1993) Izbranae tryda po iazikoznaniu i kyltyrologii (in Russian), Publisher: "Progres", "Univers", Moscow, Russia / [ЭАварА Сепир, 1993; Избранные труды по языкознанию и культурологии, М., ИзА. "Прогресс", "Универс", с. 168].

Spasov, D., (1972), The verb in the Structure of English, Sofia, Bulgaria pp. 12-14 / [A. Спасов, 1972, "ГАагольт в структурата на английски", С., С. 12-14].

Stankov, V., (1980), Glagolniat vid v balgarskia knijoven ezik (in Bulgarian), Publisher: Nayka I lzkystvo, Sofia, Bulgaria / [В. Станков, 1980, ГАаголният виА в българския книжовен език, изА. Наука и изкуство, С., с. 47].

Tihonov, A. N., (1985), Slovoobrazovatelnai slovar (in Russian) /[A. Н. Тихонов, 1985, Словообразовательный словарь, с. 47]

SILVINA MIHAYLOVA

Sofia University "St. Kliment Ohridski"

sbojidarova@yahoo.com 

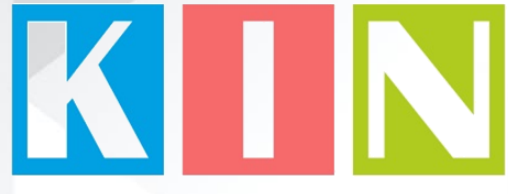

\section{ISSN: 2367-8038}

\section{Съставители \\ Петко Ст. Петков \\ Галина БогАанова}

Материалите в сборника са обект на авторско право. Разрешава се безвъзмезАното ползване на техни електронни/ хартиени копия само за мична употреба или обучение, при пьлно цитиране на текущата страница и слеА писмена Аек^арация от цитиращия за ^ипса на търговски намерения.

Научната поредица е регистрирана в НАЦИА С № 1209

() Авторски колектив, 2021

Техническо реАактори: Калина Сотирова-Вълкова Николай Ноев Паска^ Пиперков

\section{Editors}

Petko St. Petkov

Galina Bogdanova

This work is subject to copyright.

Open and free of charge use of digital/hard copies of publications is granted only for personal or educational use, with full citation of the current page, and after written declaration of the quoting side for notcommercial Intention.

Science series has been registered in NACID with No. 1209

() Authors` Group, 2021

Technical editors:

Kalina Sotirova-Valkova

Nikolay Noev

Paskal Piperkov

\section{ISSN: 2367-8038}

том 7, брой $1(10) / 2021$

vol. 7 , issue $1(10) / 2021$ 